\title{
The effect of PGF2 $\alpha$ on persistent corpus luteum in Sahiwal cows
}

\author{
Mushtaq H. Lashari and Zahida Tasawar \\ Institute of Pure and Applied Biology, Bahauddin Zakariya University, Multan, Pakistan. \\ Accepted 29 December, 2011
}

\begin{abstract}
In dairy animals, there are so many different conditions, which affect reproductive performance, and persistent corpus luteum (PCL) is one of those. It was suggested that this condition was difficult to treat and consequently result in lengthening of service period and calving interval. If this condition was not diagnosed and treated timely, it may result into permanent infertility and thereby huge loss to the breeders. The commercial availability of PGF2 $\alpha$ and its analogues had promoted management and treatment of PCL in other part of the world on different breeds of cows with variable rates of success. This study was designed to determine the response of treatment of Sahiwal cows identified as having PCL with PGF2 $\alpha$ (Dalmazin: Fatro Pharmaceutical). The present investigation has been conducted on Sahiwal cows maintained at Livestock Experimental Station, Bahadurnagar, Okara (Pakistan). The cows after $\mathbf{7 0}$ to 90 days post-partum were examined per rectum to check the condition of genitalia for PCL and this was also confirmed by progesterone assay in weekly blood samples for three weeks. All cows $(\mathrm{n}=20$ : mean weight, $402.0 \pm 6.1 \mathrm{~kg})$ sufferings from PCL were treated with $2 \mathrm{ml}$ of Dalmazin intramuscularly on the same day. It was found that $85 \%$ of animals as determined by the examination of reproductive tracts and confirmed by progesterone analysis became normal and consequently $60 \%$ were pregnant at first service whereas $25 \%$ were repeat breeder. In conclusion, the treatment of Sahiwal cows, which were suffering from PCL, with PGF2a may correct this condition successfully.
\end{abstract}

Key words: Sahiwal cow, persistent corpus luteum, progesterone, PGF2 $\alpha$

\section{INTRODUCTION}

Progesterone is a hormone produced by the cow after ovulation and can be detected from samples of milk and blood (Rowlands and Weir, 1984). Progesterone rises and falls during different periods of the cow's reproductive cycle (Lamming, 1984). A typical cycle is around 21 days in duration (Gordon, 1996). Since progesterone follows a certain pattern, it is possible to take samples from a cow and predict when the next oestrus is likely and thus when it is best to inseminate (Gordon, 1996). This is the first use of progesterone. Any problems with the cows fertility should show up in the progesterone samples and taking a reasonable number of samples can confirm an abnormal progesterone

\footnotetext{
${ }^{\star}$ Corresponding author. Email: mushtaqlashary@gmail.com.
}

pattern, this can then be used to help determine the right fertility treatment (Lamming, 1984). It has been shown that if progesterone remains low for a long period (between days 25 to 40), possibly indicating a follicular cyst and the higher concentrations of progesterone for a long period, indicates problems with the corpus luteum (Bajema et al., 1994). Once samples are taken and the progesterone levels found these can be used as an aid to the vet and farmer on the fertility situation. A further use of progesterone is to monitor levels in response to insemination to determine the pregnancy status (Gordon, 1996). A low level on the day of insemination gives a good indication that the animal was in heat and there are more chances of pregnancy (Bajema et al., 1994).

The ability of a cow to successfully mate, conceive, give birth to and raise a healthy calf each year is essential to economical beef and milk production 
(Howard and Cranfield, 1995). Causes for failures in reproduction must be identified and overcome. Research has led to the development of numerous techniques for manipulating the reproductive processes of animals and these techniques provide many options to help modern beef and milk producers accomplish their management goals (Gordon, 1996).

Following ovulation, the cells that developed within the follicle undergo a differentiation process by action of pituitary hormones. This process is called luteinization and gives rise to the second ovarian structure, the corpora lutea (pl. corpus luteum) (Rowlands and Weir, 1984; Christensen and Gillim, 1969). This structure is often referred to simply as the $C L$ and has the important function of secreting the hormone progesterone. The $\mathrm{CL}$ goes through a maturation and regression cycle much the same as the follicle (Weir and Rowlands, 1977). A blood clot-type structure known as a corpora hemorrhagicum forms in the cavity left by the ruptured follicle and is transformed into a CL by Day 5 of the cycle (Day $0=$ oestrus). The $\mathrm{CL}$ is fully functional from Day 5 to Day 15 of the cycle and then begins to regress if the female does not become pregnant (Ahmad et al., 1995). The CL regresses and no longer secretes progesterone as the follicle of the next oestrous cycle begins to develop (Stevens et al., 1995). As the CL regresses further, it becomes known as the corpus albicans and remains visible on the ovary for several subsequent cycles (Hafez, 1993).

Any condition that prolongs the period of time that blood levels of progesterone remain high will have the same effect as pregnancy in stopping the regular 21-day cycle (Gordon, 1996). Occasionally the CL does not regress normally (persistent $\mathrm{CL}$ ) even though the animal does not become pregnant and reduce the fertility and productivity. PCL continue to produce enough progesterone to prevent further follicular development, ovulation and oestrus. Severe endometritis may be associated with $\mathrm{PCL}$ due to toxic damage to the endometrium, which prevents proper secretion of luteolytic prostaglandins. This can also occur with pyometra, foetal mummification and maceration, i.e. conditions that simulate pregnancy (Boyd, 1977). Peters and Lamming (1986) reported PCL to be rare (under 2\%) in cows with normal uteri.

The prevalence of PCL was highly variable. It has been reported as low as 2\% in UK (Peters and Lamming, 1986) and as high as 33\% in China (Yu, 2001). The present study was designed to determine the prevalence of PCL in Punjab province Pakistan, and to determine the efficacy of PGF2 $\alpha$ for correcting this condition.

\section{MATERIALS AND METHODS}

The present investigations were carried out on Sahiwal cows ( $\mathrm{n}=$ 20) maintained at Livestock Experimental Station, Bahadurnagar, kara (Pakistan). This station is located at a distance of $18 \mathrm{~km}$ from
Okara City on Okara-Faisalabad Road and is $150 \mathrm{~km}$ from Lahore (Provincial capital of Punjab). The cows after 70 to 90 days postpartum were weighed $(402.0 \pm 16.1 \mathrm{~kg})$ and examined per rectum to check the condition of genitalia for PCL and this was also confirmed by progesterone assay (ELISA) in weekly milk sample for three weeks. If milk progesterone was $>5 \mathrm{ng} / \mathrm{ml}$ for three weeks, it was a case of PCL (Bajema et al., 1994).

The cows suffering from PCL were treated with PGF2 $\alpha$. For this purpose animals were treated with $2 \mathrm{ml}$ of Dalmazin (Dextrorotatory clorprostenol; Fatro Pharmaceutical) intramuscularly. The effects of

this treatment were determined by putting these animals to teasers. The animals, which showed oestrus, were inseminated. The return to service was also recorded to reveal the status of pregnancy.

The results are expressed as percentage and mean \pm SEM. The data was analysed for descriptive statistics by excel in window 97 . The comparison between different percentages was performed using Chi-squared test. The means were compared by single factor ANOVA. The $P<0.05$ was taken as statistical significance.

\section{RESULTS}

The results regarding the prevalence of $\mathrm{PCL}$ in Sahiwal cows are shown in Figure 1. It was found that $11 \%$ of the cows were suffering from this condition whereas remaining (89\%) had normal cycle.

The results about the milk progesterone concentrations in animals having PCL are shown in Figure 2. These results indicate that the milk concentrations of progesterone were higher (>5.0 ng/ml) in all the milk samples collectedfor three weeks and were not significantly $(P>0.05)$ different in different weeks. These levels showed that all these animals are suffering from PCL.

The results of the effect of PGF2 $\alpha$ treatment on PCL are shown in Figure 3. It was found that this treatment had regressed $\mathrm{PCL}$ in $85 \%$ of the animals whereas $15 \%$ were still had PCL intact. This was also confirmed by the oestrus behaviour of the animals. Moreover, of theanimals, which showed response to this treatment, $71 \%$ were pregnant and $29 \%$ had normal cycle (Figure $4)$.

\section{DISCUSSION}

The present study was designed to determine the prevalence of PCL and to find out the efficacy of PGF2 $\alpha$ $\square$ intramuscularly for correcting this condition in Sahiwal cow. The results of this study show that $11 \%$ animals were suffering from PCL. This was confirmed both by rectal palpation and milk progesterone. The concentrations of progesterone in weekly samples for three weeks was $>5.0 \mathrm{ng} / \mathrm{ml}$ which is a clear indication of PCL as described by Bajema et al. (1994). Moreover, these results show that the prevalence of PCL in Sahiwal cow was quite different from other breeds of cows as Peters and Lamming (1986) had shown as low as $2 \%$ $\mathrm{PCL}$ in UK whereas it was as high as $33 \%$ in China ( $\mathrm{Yu}$, 2001). This condition could be uneconomical for the 


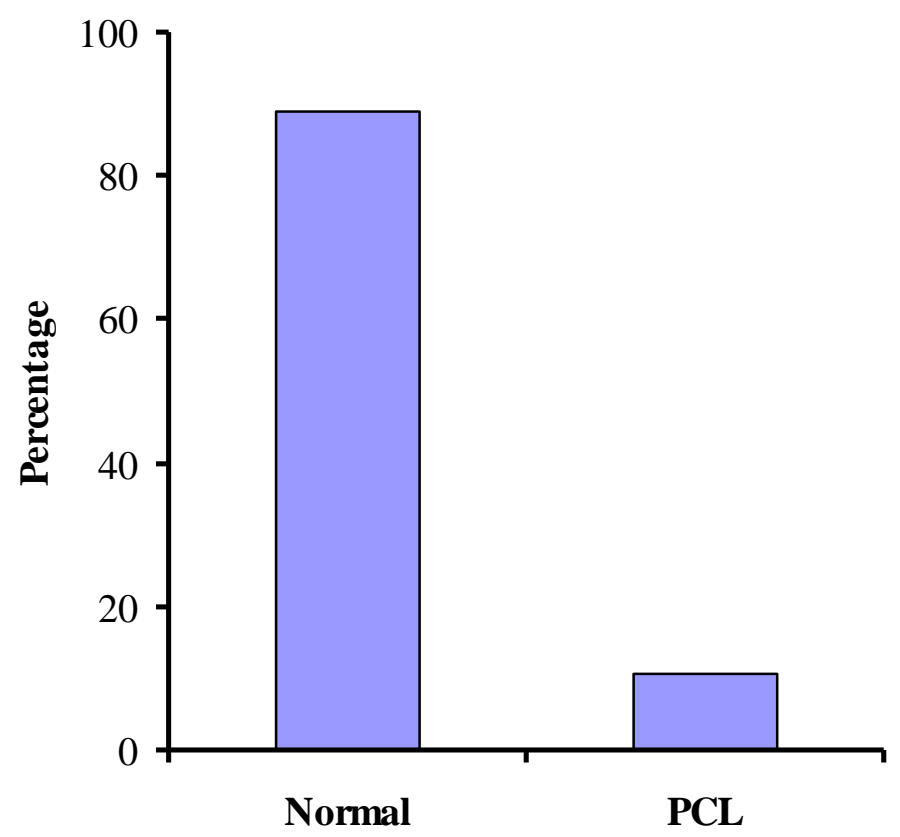

Figure 1. Prevalence of PCL in Sahiwal cow $(n=182)$.

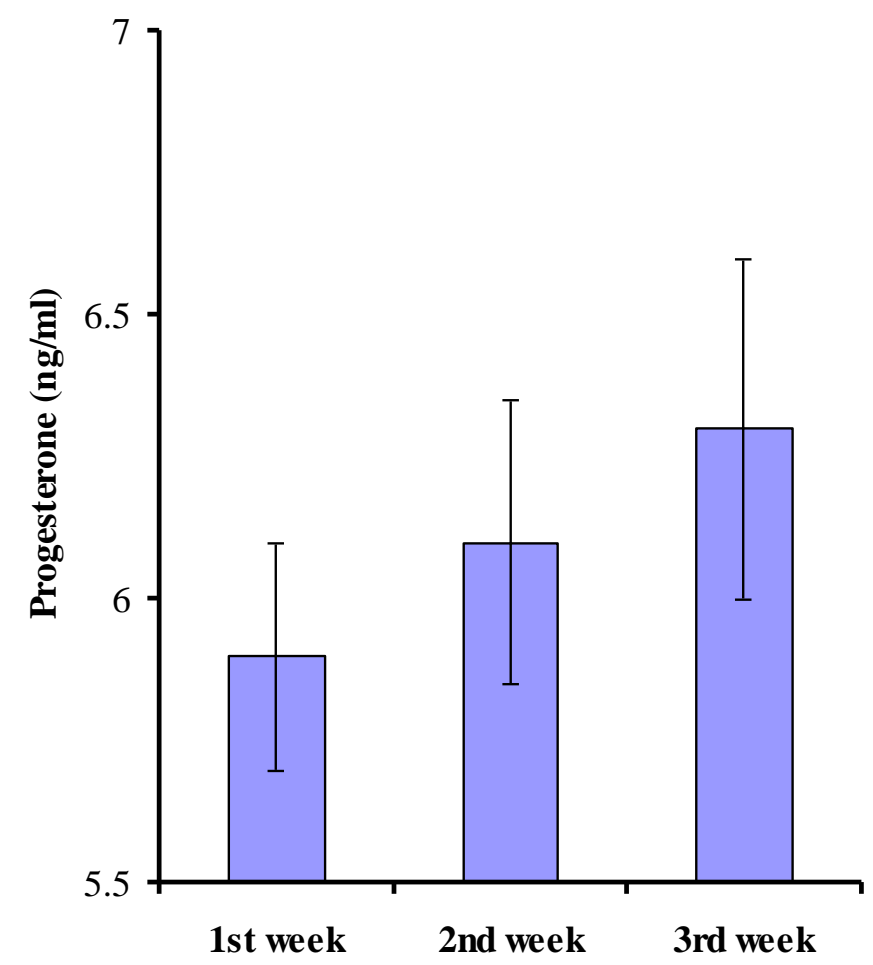

Figure 2. Plasma progesterone in cows having PCL $(n=20)$.

breeders as it may increase inter-calving interval and farmer has to feed these animals for longer duration that could be expensive and unproductive.
The results of this study demonstrate that treatment with PGF2 $\alpha$ had corrected the PCL in $85 \%$ of the cases. It has been shown that luteolysis in cow is by the 


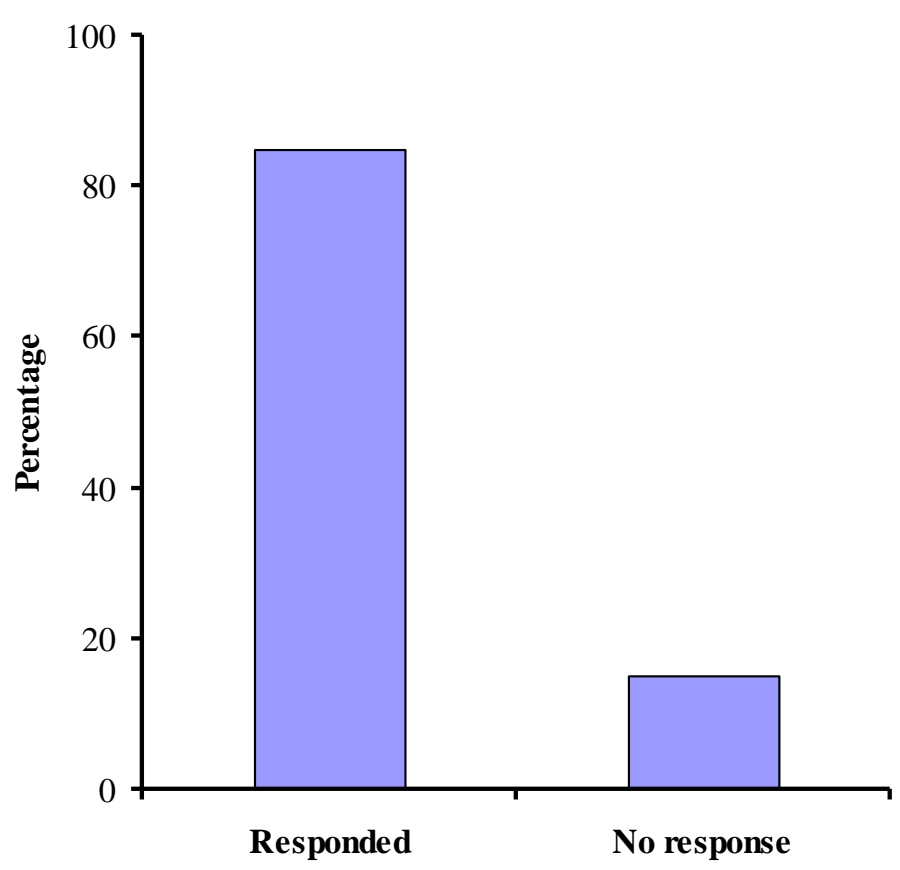

Figure 3. The effect of PGF treatment on PCL in Sahiwal cow $(n=20)$.

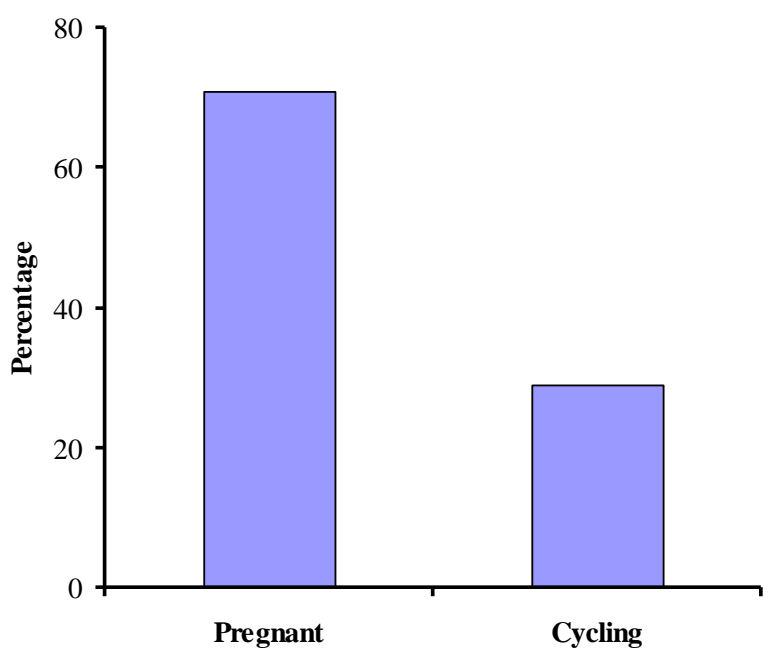

Figure 4. The pregnancy rate in animals who respond to PGF treatment $(n=17)$.

production of PGF2a (Flint et al., 1992; Poyser, 1995; Silvia et al., 1991). Several factors of maternal origin (OT=oxytocin) and embryonic origin (IFN-tau=interferontau) influence prostaglandin production to maintain $\mathrm{CL}$ (pregnancy) or its demise (return to oestrus) (Asselin et al., 1997). OT binds to OT receptors (OTR) in endometrium to activate cyclooxygenase-2 (COX-2) and the production of PGF2a (Asselin et al., 1997; Silvia et al., 1991). Several studies have shown that the levels of

PGF2 $\alpha$ are reduced in the presence of a viable conceptus (or its signal) in vivo and in vitro (Bazer, 1992; Danet-Desnoyers, 1994; Lashari and Tasawar, 2010). In contrast, PGF2 $\alpha$ could be a luteotrophic agent and may be a luteo-protective signal to neutralise a luteolytic effect of PGF2a (Emond et al., 1998).

The longer survival of PCL could be attributed either to weaker luteolytic signal or strong luteotrophic support. It has been shown that treatment with $\mathrm{PGE}_{2}$ protects the $\mathrm{CL}$ from spontaneous regression (Pratt et al., 1977) as well as luteolysis induced by exogenous PGF2 $\alpha$ 
(Henderson et al., 1977). The results of the present study indicate that after exogenous PGF2 $\alpha$ treatment, 85\% animals showed response by accepting the male (teaser). It is assumed that in these cows, the $\mathrm{PGE}_{2}$ concentrations were not that high which could protect the PCL in the presence of exogenous PGF2 $\alpha$ treatment and thereby $\mathrm{PCL}$ regressed. Moreover, in remaining cows (15\%) the concentrations of $\mathrm{PGE}_{2}$ were higher and in this condition $2 \mathrm{ml}$ of PGF2 $\alpha$ were not enough to overcome the antiluteolytic effect of $P G E_{2}$. To verify this assumption some more work need to be done. However, this possibility gets support from earlier report of Boyd (1977) who found that severe endometritis may be associated with a PCL due to toxic damage to the endometrium, which prevents proper secretion of luteolytic prostaglandins.

The results of this study also indicate that majority of animals who showed response to this treatment were pregnant to first service $(71 \%)$ and remaining were repeat breeders (29\%). In a way after PGF2 $\alpha \square$ treatment $85 \%$ of the cows having PCL was breeding normally. It indicates that this treatment had the potential to improve the fertility in lactating cows and thereby enhance the life time productivity of Sahiwal cows.

In conclusion, the results of the present study shows that the treatment with PGF2 $\alpha \square$ in Sahiwal cow corrected PCL in $85 \%$ animals and majority of these animals becomes pregnant and thereby improve the fertility and productivity of these animals.

\section{REFERENCES}

Ahmad N, Schrick FN, Butcher RL, Inskeep EK (1995). Effect of persistent on early embryo losses in beef cows. Biol. Reprod., 52: 1129-1135.

Asselin E, Drolet P, Fortier MA (1997). Cellular mechanism involved during oxytocin-induced PGF2 a production in endometrial epithelial cells in vitro: Role of cyclooxygenase-2. Endocrinology. 138: 47984805.

Bajema DH, Hoffman MP, Aitchison TE, Fordo SP (1994). Use of cowside progesterone tests to improve reproductive performance of high producing dairy cow. Theriogenology, $42: 765-771$.

Bazer FW (1992). Mediators of maternal recognition of pregnancy in ruminants. Proc. Soc. Exp. Biol. Med., 199: 373-384.

Boyd H (1977). Anoestrus in cattle. Vet. Rec., 100: 150-153.

Christensen K, Gillim SW (1969). The correlation of the fine structure and function of steroid-secreting cells, with emphasis on those of the gonads. In: The gonads. (ed. K.McKerns). Appleton Press. New York.
Danet-Desnoyers G, Wetzels C, Thatcher WW (1994). Natural and recombinant bovine interferon tau regulate basal and oxytocin induced secretion of Prostaglandins $F_{2 a} E_{2}$ by epithelial cells and stromal cells in the endometrium. Reprod. Fertil. Dev., 6: 193-202.

Emond V, Murphy BD, Fortier MA, Lambert RD (1998). Prostaglandin $E_{2}$ regulates both interleukin-2 and granulocyte-macrophage colony stimulating factor gene expression in bovine lymphocytes. Biol. Reprod., 58: 143-151.

Flint AP, Stewart HJ, Lamming, GE, Payne JH (1992). The role of the oxytocin receptors in the choice between cyclicity and gestation in ruminants. J. Reprod. Fertil. (Suppl)., 45: 53-58.

Gordon I (1996). Controlled reproduction in cattle and Buffaloes. CAB International. Wellingford, UK.

Hafez ESE (1993). Reproduction in Farm Animals. Lea \& Febiger. Philadelphia.

Henderson KM, Scaramuzzi RJ, Baird DT (1977). Simultaneous infusion of prostaglandin $E_{2}$ antagonizes the luteolytic action of prostaglandin $\mathrm{F}_{2 \alpha}$ in vivo. J. Endocrinol., 72: 379-383.

Howard WH, Cranfield J (1995). Ontario beef producers attitudes about artificial insemination. Can. J. Agric. Eco. 43: 305-314.

Lamming GE (1984). Marshall's Physiology of Reproduction. Churchill Livingstone. London.

Lashari MH, Tasawar Z (2010). The effect of GnRH given on day of mating on ovarian function and reproductive performance in lohi sheep. Pak. Vet. J., 30. 29-33.

Peters AR, Lamming GE (1986). Regulation of ovarian function in the postpartum cow: an endocrine model. Vet. Rec., 118: 236-239.

Poyser NL (1995). The control of prostaglandin production by the endometrial in relation to luteolysis and menstruation. Prostaglan. Leukot. Essent. Fatty Acids, 53: 147-195.

Pratt BR, Butcher RL, Inskeep EK (1977). Antiluteolytic effect of the conceptus and of $\mathrm{PGE}_{2}$ in ewes. J. Anim. Sci. 45: 784-791.

Rowlands IW, Weir BJ (1984). Mammals: Non-primate Eutherians. In: Marshall's Physiology of Reproduction. Vol. 1. (ed. G.E.Lamming). Churchill Livingstone. London.

Silvia WJ, Lewis GS, McCracken JA, Thatcher WW, Wilson LJr (1991). Hormonal regulation of uterine secretion of prostaglandin $F_{2}$ a during luteolysis in ruminants. Biol. Reprod., 45: 655-663.

Stevens RD, Seguin BE, Momont HW (1995). Evaluation of the effects of route of administration of cloprostenol on synchronization of estrus in diestrous in dairy cattle. J. Am. Vet. Med. Assoc., 207: 241-216.

Weir BJ, Rowlands IW (1977). Ovulation and atresia. In: The ovary. (eds. S.Zuckerman \& B.J.Weir). Academic Press. New York.

Yu SJ (2001. Reproductive Endocrinology of the Female Yak. In: Recent Advances in Yak Reproduction. (eds. X.X.Zhao \& R.C.Zhang). International Veterinary Information Service. Ithaca. 